\title{
EXPERIMENTAL INVESTIGATION ON HEAT TRANSFER AND PRESSURE DROP CHARACTERISTICS OF AIR FLOW OVER A STAGGERED FLAT TUBE BANK IN CROSSFLOW
}

\author{
M. Ishak ${ }^{1,2}$, Tahseen Ahmad Tahseen ${ }^{1,3}$ and Md. Mustafizur Rahman ${ }^{1,2}$ \\ ${ }^{1}$ Faculty of Mechanical Engineering, University Malaysia Pahang \\ 26600 Pekan, Pahang, Malaysia \\ Phone : +609-424-2246 ; Fax : +609-424-2202 \\ ${ }^{2}$ Automotive Engineering Centre, Universiti Malaysia Pahang, \\ 26600 Pekan, Pahang, Malaysia \\ ${ }^{3}$ Department of Mechanical Engineering, College of Engineering, \\ University of Tikrit, Tikrit, Iraq \\ Email: tahseen444@gmail.com
}

\begin{abstract}
This paper presents an experimental investigation into the heat transfer and pressure drop characteristics of air flow in a staggered flat tube bank in crossflow with laminarforced convection. Measurements were conducted for sixteen tubes in the direction of flow and four tubes in rows. The air velocity varies between $0.6-1.0 \mathrm{~m} / \mathrm{s}$ and the Reynolds number varied from 373 to 623 . The total heat flux supplied in all tubes are changed from 967.92 to $3629.70 \mathrm{~W} / \mathrm{m}^{2}$. The results indicate that the average Nusselt number for all the flat tubes increased by $11.46-46.42 \%$, with the Reynolds numbers varying from 373 to 623 at the fixed heat flux. The average Nusselt number increased by $21.39-84 \%$, and the total heat flux varyied between $967.92-3629.70 \mathrm{~W} / \mathrm{m}^{2}$ with a constant Reynolds number $R e=498$. In addition, the pressure drop decreased with an increase in the Reynolds number. A new mean Nusselt number-Reynolds number correlation was found, and the correlation yielded good predictions for the measured data with a confidence interval of $98.9 \%$.
\end{abstract}

Keywords: Experimental study; forced convection; staggered flat tube; measurement.

\section{INTRODUCTION}

Heat transfer and fluid flow in tube bundles represents an idealisation of many industrially-important processes. Tube banks are openly employed in crossflow heat exchangers, the design still relies on empirical correlations of pressure drop and heat transfer. Heat exchangers with tube bundles in crossflow are of a major operating interest in many chemical and thermal engineering processes (Buyruk et al., 1998; Incropera et al., 2007; Kaptan et al., 2008; Srinivasa Rao et at., 2011; Liang and Papadakis, 2007; Mandhani et al., 2002; Wang et al., 2000). Flat tubes, despite not having been assessed to the same extent, play a significant role in many technical applications, such as automotive radiators and modern heat exchangers. Designs have recently been provided for use in air conditioning systems for automotive evaporators and condensers. Recent developments in automotive aluminium manufacturing technology have made the cost of the construction of flat tube heat exchangers more propitious (Webb and Kim, 1994; Suryanarayana et al., 2011; Muthucumaraswamy et 
al., 2012). In addition, flat tube heat exchangers are expected to offer the best air-side heat transfer coefficients and minimum air-side pressure drops compared with circular tube heat exchangers. The pressure drop in flat tubes is expected to be less than circular tubes due to a smaller wake area. For the same reason, noise and vibration are expected to be less in flat tube heat exchangers compared to circular tube heat exchangers. Tahseen et al. (2012a,b, 2013) have conducted numerical studies on incompressible, steady state flows using the body fitted coordinate (BFC). The first study concerns heat transfer over a series of flat tubes between two parallel plates. In the second study examines heat transfer over two staggered flat tubes, and the third study looks at heat transfer over the in-line banks of a circular tube. The studies show that the Nusselt number increases with an increase in Reynolds number. In this paper, the cooling process was experimentally examined with a staggered flat tube configuration with a diameter ratio of the tube $D / d=1.85$. The Reynolds number for external air flow was based on the mean free stream air velocity and the outer hydraulic diameter the tube, which varied from 373 to 623 , and the heat flux supply to all tubes ranged between 967.92-3629.70 W/m ${ }^{2}$. Experiments were conducted $\mathrm{Tt}$ detect the effects of the Reynolds number on the air pressure drop across the flat tube banks and the heat transfer rate.

\section{EXPERIMENTAL SETUP AND DETAILS}

The flat tube arrangement was made from aluminum, with a small diameter of $10 \mathrm{~mm}$ and larger diameter or $18.5 \mathrm{~mm}$, with a tube thickness of $1 \mathrm{~mm}$. The outer hydraulic diameter $D_{h}=13.5 \mathrm{~mm}$, and all tubes had a length of $200 \mathrm{~mm}$. Double electric heaters were inserted inside the tubes to simulate the heat flux originating from a hot fluid. For all the arrangements, four rows were placed in the direction of external flow over all tubes, as shown in Figure 1(a). Sixteen flat tubes were then assembled according to the design presented in a drawer from Teflon type Polytetraflu-oroethylene (PTFE), which is the test module. Losses were minimised by holding the end of the flat tube between two Teflon walls separated by a distance $L=200 \mathrm{~mm}$, as shown in Figure 1(b-c).

Thirty-two heating elements were used, consisting of cylindrical electric heaters, each rated at $50 \mathrm{~W}$ up to $850 \mathrm{~W}$ with $220 \mathrm{~V}$ AC. The outside diameter of the electric heaters is $8 \mathrm{~mm}$ and their length is $200 \mathrm{~mm}$, the diameter being small enough to insert into the aluminium tubes. The heaters were connected in parallel, and two variable AC voltage sources used that produced voltages ranging from 0 to $125 \mathrm{~V}$. The maximum power supply was $220 \mathrm{~V}$ and a maximum current of $2.5 \mathrm{~A}$ was supplied from the variable AC voltage sources - LOADSTAR 850 models. The current and voltage measurements were performed with a current clam meter and volt measurement meter, respectively. Fifteen thermistors of type EPCOS B57164K0102J NTC (resistance 1000 $\Omega$ at $25{ }^{\circ} \mathrm{C}$ ) were placed in the test module. All thermistors were placed in the centre between the side walls of the wind tunnel, and along the midline of the channels. Four thermistors were placed at the arrangement inlet $\left(T_{i n, 1}-T_{i n, 4}\right)$, four at the surfaces of the tubes $\left(T_{s, 1}-T_{s, 4}\right)$ and five at the outlet $\left(T_{\text {out }, 1}-T_{\text {out }, 5}\right)$ in one channel. An additional thermistor $\left(T_{b e f}\right)$ was placed in the extended region at $400 \mathrm{~mm}$ before the test module, in order to measure the temperature of the free stream.

Thermistors at the surface of the tubes showed that the difference between the tubes in one channel is negligible, and are within a $\pm 0.57{ }^{\circ} \mathrm{C}$ margin with respect to the average of the four thermistors. Finally, the thermistor placed in the extended region for measuring the free stream temperatures measured a $\pm 0.22{ }^{\circ} \mathrm{C}$ margin with respect to the 
average temperature measured in the inlet arrangement, for all the tests carried out in this work. The velocity measurements were taken with a vane-type hot wire anemometer; model YK-2004AH, which was placed in the extended flow region as shown in Figure 2, for the range of $0.2-20 \mathrm{~m} / \mathrm{s}$. The resolution of reading and uncertainty in the free steam velocity $U_{\infty}$ was $\pm(1-5 \%,+0.1 \mathrm{~m} / \mathrm{s})$. The velocity of the free stream $U_{\infty}$ varied between $0.6-1.0 \mathrm{~m} / \mathrm{s}$ in this study. The pressure drop measurements were taken using a differential pressure meter, model TESTO 510, with an operating range of $0-100 \mathrm{kPa}$, a resolution of $1 \mathrm{~Pa}$ of reading and an accuracy of $\pm 0.3 \mathrm{~Pa}$. The differential pressure measurements had the finality of measuring the pressure drop across each of change in the free stream velocity for all experiments, as shown in Figure 2. The experimental work includes the obtainment of temperature data using a highly-accurate TESTO thermometer, model TESTO 110, with a nominal range of $-50{ }^{\circ} \mathrm{C}$ to $+150{ }^{\circ} \mathrm{C}$, temperature thermometer resolution of $0.1{ }^{\circ} \mathrm{C}$ and an accuracy around $\pm 0.2{ }^{\circ} \mathrm{C}$. The thermistor was calibrated in the laboratory to determine the limits of deviation.

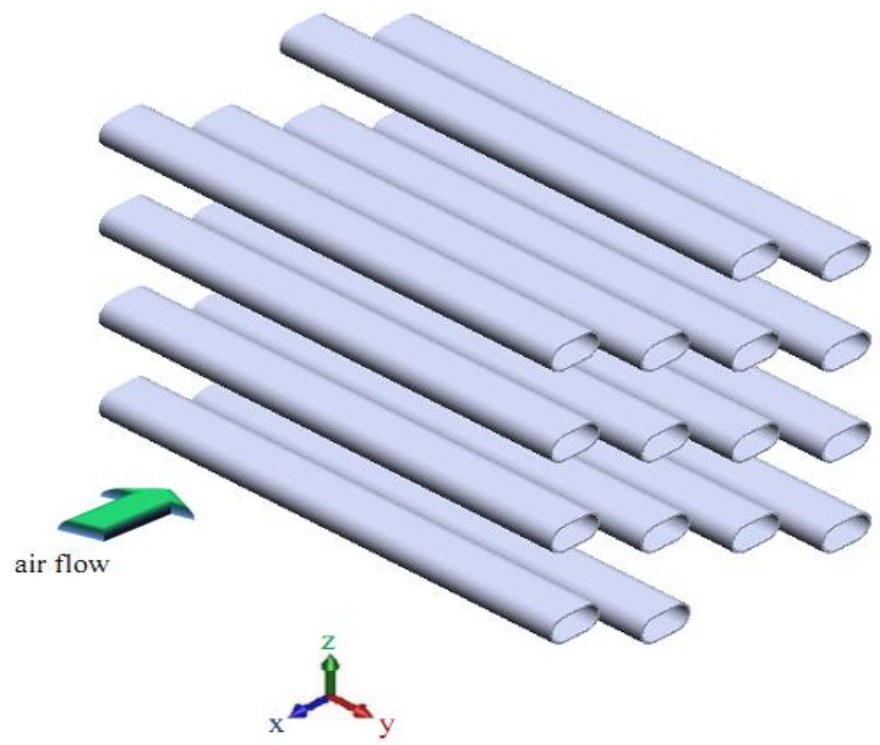

(a)

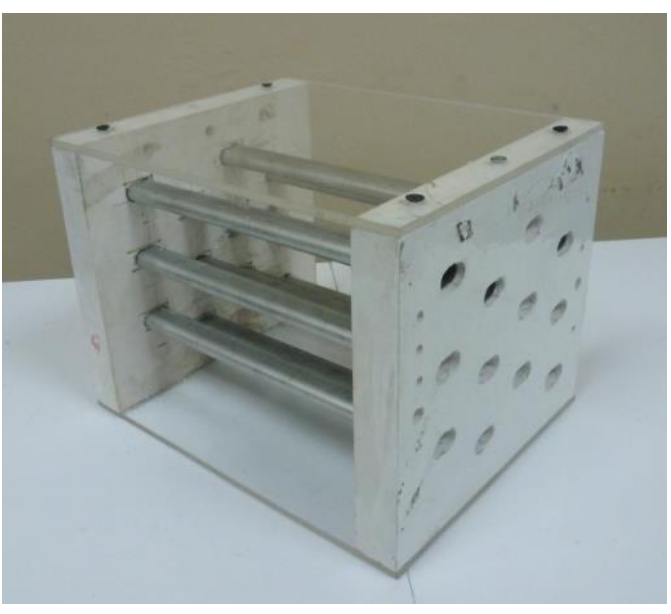

(b)

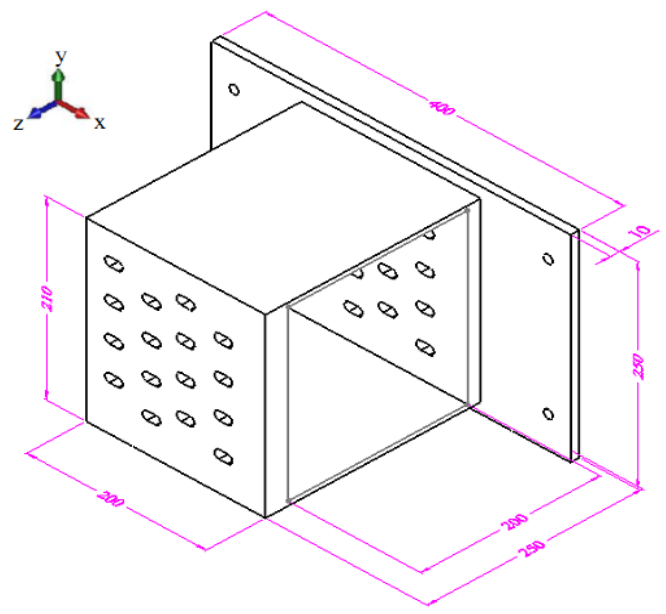

(c) 
Figure 1. Experimental test models; (a) tube configuration; (b) Teflon module; and (c) schematic of Teflon module with dimensions (all dimensions in $\mathrm{mm}$ ).

The thermistor was immersed in four types of fluid: distilled water, n-Hexane, Metghylated Spirit and Toluene. After that, each fluid is separately heated to reach its boiling point and then the values are recorded as shown in Figure 3 (Collett and Hope, 1983). Each run was started by selecting the voltage and current supply to the cartridge heaters and air velocity of the free stream, then we waited 2.5-3.0 hours while monitoring the changes in voltage, current, $T_{\text {bef }}, T_{i n, 1}-T_{i n, 4}, T_{s, 1}-T_{s, 4}$ and $T_{\text {out }, 1}-T_{\text {out }, 5}$. The relative changes in the voltage, current and temperature were less than $0.5-0.8 \%, 2-$ $2.2 \%$ and $0.044-0.075 \%$, respectively. These changes were estimated relatively by repeating the same value $R e_{D h}$ value within 7.5-9 hours. It should be noted that these relative changes are small when compared with the uncertainties in the relevant measurements.

In this experiment a steady state flow is assumed. To investigate in the following relations for the relevant air properties and used in the following calculations. It is based on data and valid for the range of temperatures $250 K \leq\left(\bar{T}_{\text {in }}+\bar{T}_{\text {out }}\right) / 2 \leq 400 K$ (Collett and Hope, 1983);

$$
\begin{gathered}
\rho=1.05269+4.895 \times 10^{-4}\left(\frac{\bar{T}_{\text {in }}+\bar{T}_{\text {out }}}{2}\right) \\
k=\left[3.71452+7.495 \times 10^{-2}\left(\frac{\bar{T}_{\text {in }}+\bar{T}_{\text {out }}}{2}\right)\right] \times 10^{-3} \\
\mu=\left[4.99343+4.483 \times 10^{-2}\left(\frac{\bar{T}_{\text {in }}+\bar{T}_{\text {out }}}{2}\right)\right] \times 10^{-6} \\
C p=\left[9.8185+7.7 \times 10^{-4}\left(\frac{\bar{T}_{\text {in }}+\bar{T}_{\text {out }}}{2}\right)\right] \times 10^{2}
\end{gathered}
$$

where

$$
\begin{aligned}
& \bar{T}_{\text {in }}=\frac{1}{n} \sum_{i=1}^{n}\left(T_{\text {in }}\right)_{i}, \quad n=4 \\
& \bar{T}_{\text {out }}=\frac{1}{n} \sum_{i=1}^{n}\left(T_{\text {out }}\right)_{i}, \quad n=5
\end{aligned}
$$

The electrical heat gain rate was calculated with Eq. (5).

$$
Q_{\text {elect }}=V \times I
$$

The steady state heat balance of the electrically heated test surface can be written as Eq. (6).

$$
Q_{\text {elect }}=Q_{\text {conduction }}+Q_{\text {radiation }}+Q_{\text {convection }}
$$




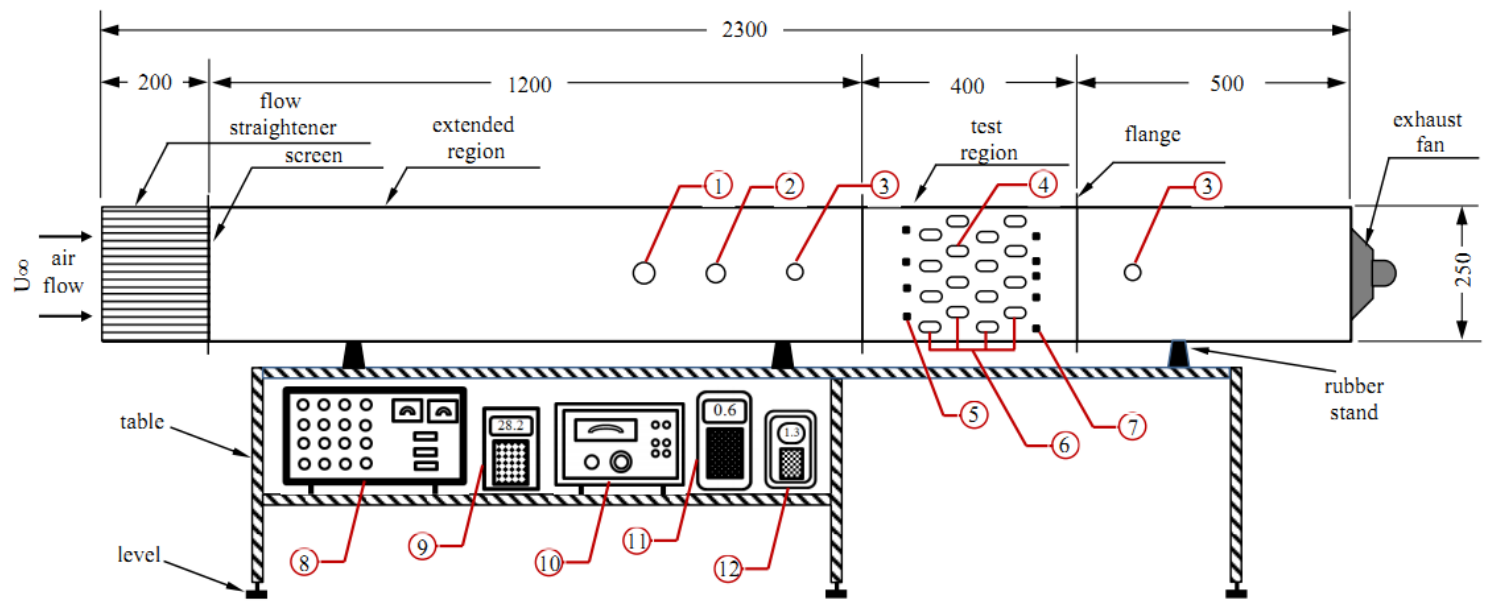

$\begin{array}{llllll}1 & \text { Location of the anemometer } & 2 & \text { Location thermistor before test rig } & 3 & \text { location of the differential pressure } \\ 4 & \text { Flat tube with heater } & 5 & \text { Inlet thermistor } & 6 & \text { Thermistor at the surface of tube } \\ 7 & \text { Outlet thermistor } & 8 & \text { Switch board } & 9 & \text { Digital thermometer } \\ 10 & \text { Power supply } & 11 & \text { Hot wire anemometer } & 12 & \text { Digital manometer }\end{array}$

Figure 2. Schematic display of the experimental approach (all dimensions in $\mathrm{mm}$ ).

The heat transfer from the system is as follows:

i) Conduction between the laboratory and the wall of the tubes was neglected due to the extremely low thermal conductivity of the air $\left(0.23 \mathrm{~W} / \mathrm{m}{ }^{\circ} \mathrm{C}\right)$, of Teflon and the negligible temperature difference between the laboratory and the outer walls of the Teflon.

ii) Radiation heat transfer between the surfaces of the tubes and the surroundings were also neglected. Based on the measurement of $\left(\bar{T}_{\text {in }}+\bar{T}_{\text {out }}\right) / 2$ and the mean $\bar{T}_{s}$ the radiation transfer coefficients were estimated as (Khan et al., 2004):

$$
\bar{h}_{\text {rad }}=\varepsilon \times \sigma \times\left[\left(\left(\frac{\bar{T}_{\text {in }}+\bar{T}_{\text {out }}}{2}\right)^{2}+\left(\bar{T}_{s}\right)^{2}\right) \times\left(\left(\frac{\bar{T}_{\text {in }}+\bar{T}_{\text {out }}}{2}\right)+\bar{T}_{s}\right)\right]
$$

where $\bar{T}_{s}=\frac{1}{n} \sum_{i=1}^{n}\left(T_{s}\right)_{i}, n=4$

For a commercial aluminium tube with an emissivity $\varepsilon \approx 0.028$ (Collett and Hope, 1983), $\bar{h}_{\text {rad }}$ was found to range between $0.174-0.205 \mathrm{~W} / \mathrm{m}^{2}{ }^{\circ} \mathrm{C}$, in approximately $0.0102-0.15 \%$ of the air side convection heat transfer coefficient, $\bar{h}$. Thus the heat transfer between the air and the surface of the tubes was in fact due to convection, and the mechanism of Eq. (6) was rewritten (Naik et al., 1987):

$$
Q_{\text {total }} \cong \bar{h} \times A_{s} \times\left[\bar{T}_{s}-\left(\frac{\bar{T}_{\text {out }}+\bar{T}_{\text {in }}}{2}\right)\right]
$$

where $A_{s}=n t \times[\pi \times d+2 \times(D-d)] \times L$ 
where $n t$ is the number of tubes, the inlet air temperature $\bar{T}_{i n}$ was the variable (22.86-26.01 ${ }^{\circ} \mathrm{C}$ ), and $\bar{T}_{s}$ was the average temperature of the surface of the tubes. For the steady state condition, the overall heat transfer rate, $Q_{\text {elect }}$, was equal to the electrical heat supply, $Q_{\text {elect }}$. From Eq. (6), the average heat transfer coefficient was determined as Eq. (9):

$$
\bar{h}=\frac{Q_{\text {elect }}}{A_{s} \times\left[\bar{T}_{s}-\left(\frac{\bar{T}_{\text {out }}+\bar{T}_{\text {in }}}{2}\right)\right]}
$$

The dimensionless average heat transfer coefficient of the air, namely the Nusselt number, was calculated from Eq. (10):

$$
\overline{N u}=\frac{\bar{h} \times D_{h}}{k}
$$

where the hydraulic diameter:

$$
D_{h}=\frac{4 \times(\text { cross }- \text { sectional area })}{\text { wetted perimeter }}=\frac{4 \times\left[\frac{\pi}{4} d^{2}+(D-d) \times d\right]}{\pi \times d+2 \times(D-d)}
$$

The Reynolds number is defined as Eq. (12):

$$
R e_{D h}=\frac{\rho \times U_{\infty} \times D_{h}}{\mu}
$$

The dimensionless pressure drop is defined as Eq. (13):

$$
C_{p}=\frac{2 \times \Delta P}{\rho \times\left(U_{\infty}\right)^{2} \times n t}
$$

where $n t$ is the number of tubes

Experimental uncertainty issues were dealt with in Journal of Heat Transfer (1993), Dieck (1997) and in Holman (2012). There is more than one way to estimate the uncertainty in the experimental results and has presented by Kline and McClintock. The few sample calculations here. The independent parameters are the tube dimensions, temperature, velocity, etc., and the dependent parameters (like $D_{h}, R e, Q_{\text {elect }}, \mathrm{Nu}$, etc.) are independent functions of other measured parameters, an uncertainty for the independent variable separates them, according to their functional relationship. The example chosen is the case of the electric power $\left(Q_{\text {elect }}\right)$.

$$
Q_{\text {elect }}=V \times I
$$




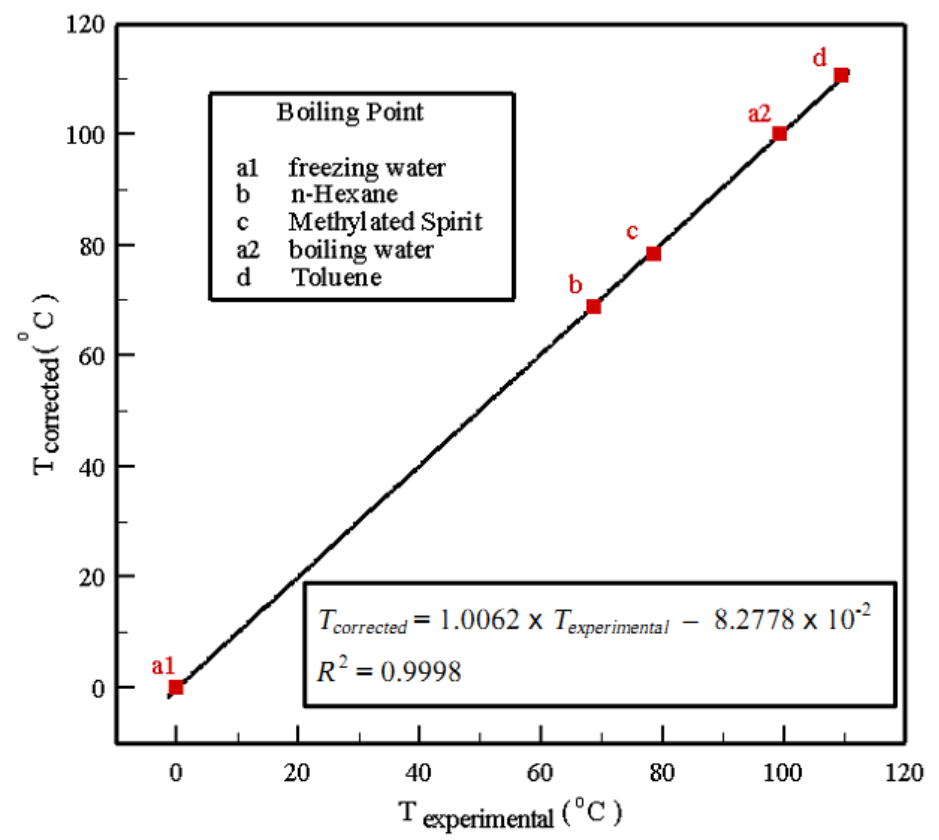

Figure 3. Calibration of the thermistor.

The uncertainties in the current and voltage propagate in $Q_{\text {elect }}$, and can be estimated in terms of relative or absolute values (\%), as follows:

Relative

$$
\left(\frac{U_{Q_{\text {elect }}}}{Q_{\text {elect }}}\right)=\sqrt{\left(\frac{U_{v}}{V}\right)^{2}+\left(\frac{U_{I}}{I}\right)^{2}}
$$

Or absolute

$$
U_{Q_{\text {elect }}}=\sqrt{\left(\frac{\partial Q_{\text {elect }}}{\partial V} U_{v}\right)^{2}+\left(\frac{\partial Q_{\text {elect }}}{\partial I} U_{I}\right)^{2}}
$$

The uncertainties in determining $D_{h}, Q_{\text {elect }}, R e, N u, C_{P}$, were estimated and found to be approximately $5.68 \%, 2.26 \%, 4.2 \%, 3.91 \%$, and $2.79 \%$ respectively.

\section{RESULTS AND DISCUSSION}

This section presents the experimental results for laminar-forced convection heat transfer across tube bundles with a staggered configuration. The main objective of this study is to determine the Reynolds number-Nusselt number relationship and the heat flux input-Nusselt number relationship. Figure 4 shows the variations in mean Nusselt number $(\mathrm{Nu})$ with Reynolds number $(\mathrm{Re})$ for different heat flux supplies. From Figure 4 it can be seen that $N u$ increases with increases in $R e$ for all heat flux supplies. The reason being the temperature difference between the hot surface of the tube and air flow increasing as the $R e$ increases. Also, the time of contact between the air flow and hot surface of the tube is not enough and decreases with an increasing $R e$. In addition, the $\mathrm{Nu}$ number increases almost linearly with an increase in $R e$. The variation in $N u$ with 
the total heat flux supply at different free stream velocities is plotted in Figure 5. The figure shows the $\mathrm{Nu}$ increasing nearly linearly with the increasing total heat flux supply. $\mathrm{Nu}$ increases with an increase in the free stream velocity of the air flow.

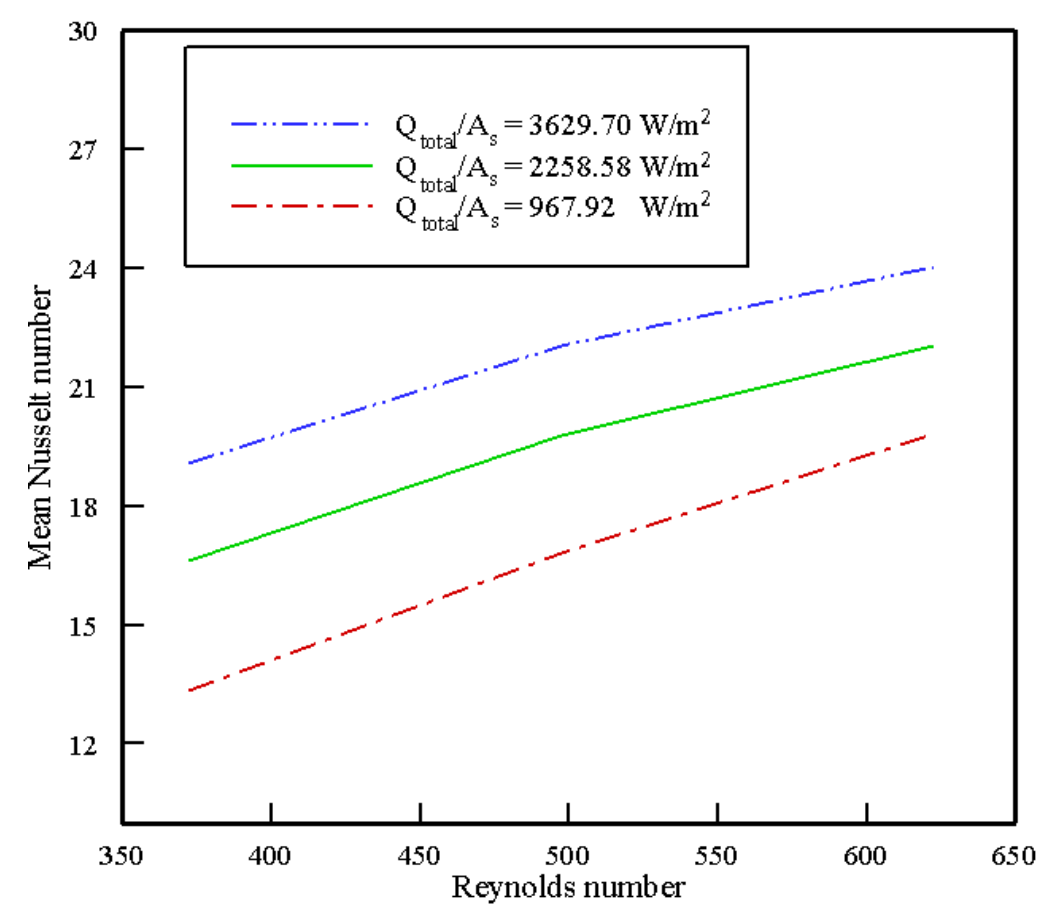

Figure 4. Effect $R e$ on $N u$ at different heat flux supplies.

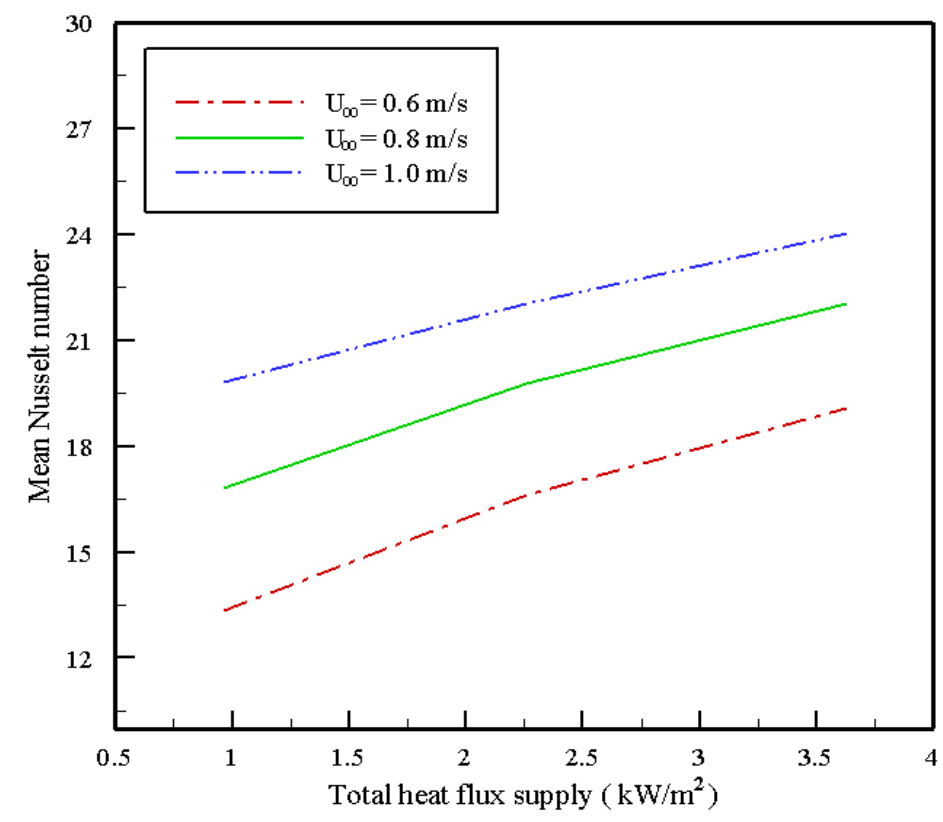

Figure 5. Effect of total heat flux on $\mathrm{Nu}$ with different free stream air velocities.

The effect of the Reynolds number on the pressure drop $(\Delta P)$ and the dimensionless pressure drop $\left(C_{P}\right)$ are shown in Figure 6. Figure 6(a) illustrates $\Delta P$ increasing linearly with an increase in $R e$. This increase may be due to variations in the air properties, as the air density decreases with an increasing temperature. The heating 
of the air means heating cold air, which initially has a slightly higher density. In this circumstance the density estimated at average air temperature between inlet and outlet $\left(\bar{T}_{\text {in }}+\bar{T}_{\text {out }}\right) / 2$, was relatively highest in this work. The $C_{P}$ decreased progressively and approaches the value of $0.14 R e$ increase and awarding an increase in the decreasing rate of $C_{P}$ as shown in Figure 6(b).

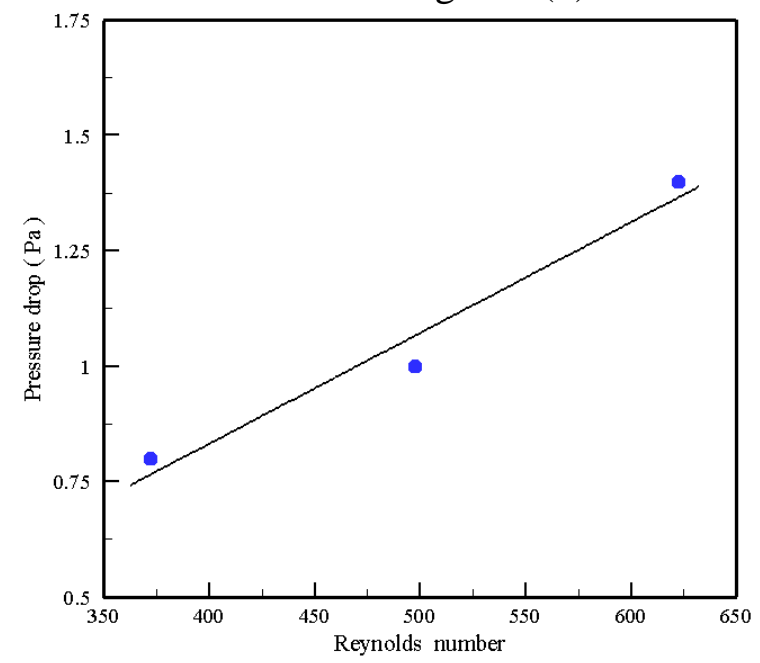

(a)

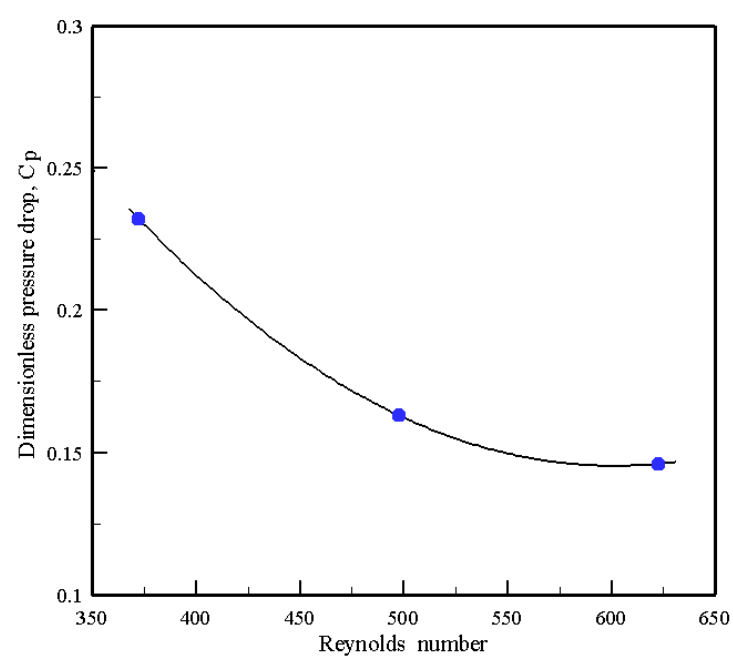

(b)

Figure 6. Effect of Reynolds number on (a) pressure drop and (b) dimensionless pressure drop, across the test section.

The relationship between the mean Nusselt number and the Reynolds number is plotted in Figure 7. The $N u$ increases with the increases $R e$ in the power law formalises. The relationship between them was determined as

$$
\overline{N u}=C_{1} \times R e^{C 2}
$$

where $C_{1}$ and $C_{2}$ are the coefficients of the fitting curve as listed in Table 2. Figure 6 presents a comparison between the present experimental work and the results two previous works. It is shows that the experimental results agree well with Hausen (1983) and Khan et al. (2006). It is evident that the Reynolds number is major factor affecting the heat transfer rate.

Table 1. The coefficients of curve fitting for calculating equation (17).

\begin{tabular}{cccc}
\hline $\begin{array}{c}\text { Total heat flux } \\
\left(\mathrm{W} / \mathrm{m}^{2}\right)\end{array}$ & $C_{1}$ & $C_{2}$ & $R^{2}$ \\
\hline 967.921 & 0.061 & 0.900 & 0.989 \\
2258.48 & 0.440 & 0.610 & 0.988 \\
3629.70 & 1.584 & 0.422 & 0.985 \\
\hline
\end{tabular}




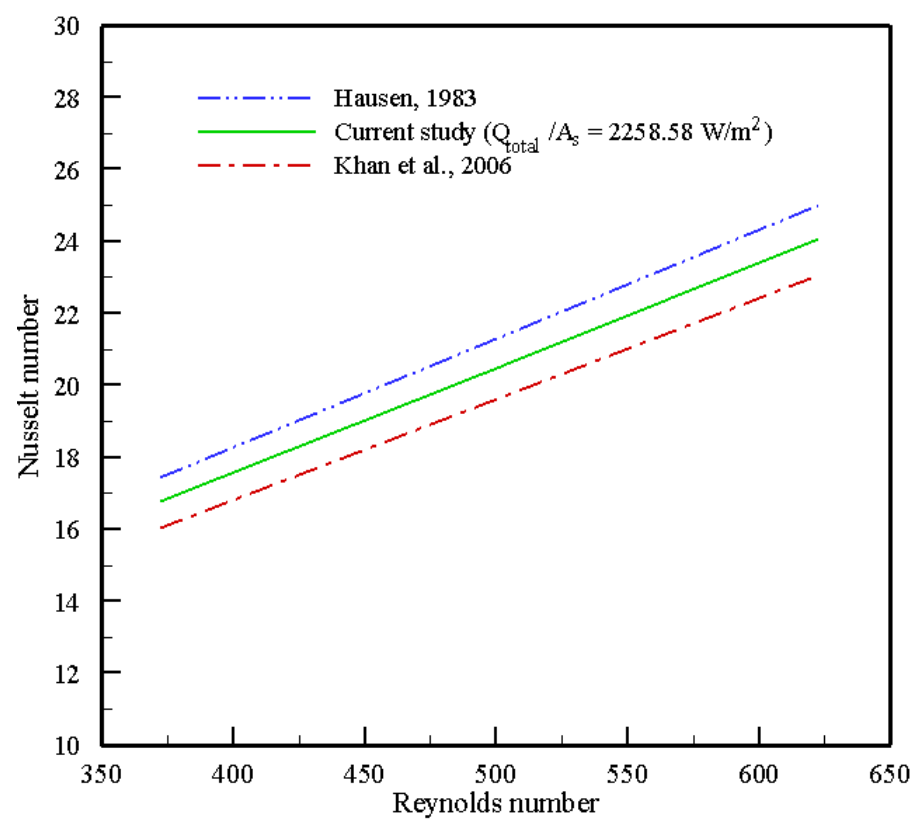

Figure 7. Comparison between the current study and different empirical correlations for Nusselt number.

\section{CONCLUSIONS}

The forced convection crossflow heat transfer of cold air over an array of hot aircarrying flat tubes has been study experimentally. The Reynolds number changes in response to changes in the average free stream velocity, and the heat flux for the system changes in response to the changes in the voltage supply. The results can be summarised as:

i) The average heat transfer coefficients for the flat tube bundles depend on the mean free stream velocity of the air and the heat flux supply.

ii) The heat transfer rate increases with the increase in mean air velocity.

iii) The mean Nusselt number for all the flat tubes is increased by $11.46-46.42 \%$ in the Reynolds numbers range of 373 to 880 for the fixed heat flux. Also, they increase between $21.39-84 \%$ for a $R e=623$, and the heat flux supply ranges between 967.9 to $3629.7 \mathrm{~W} / \mathrm{m}^{2}$.

iv) The pressure drop increases with an increase in the mean velocity of the air flow and the dimensionless pressure drop decreases with an increase in mean air flow.

v) Finally, the Nusselt number-Reynolds number correlation was found to be $N u=C_{1} \times R e^{C_{2}}$ with a mean error range $\left(R^{2}\right)$ of 0.985 to 0.989 .

\section{ACKNOWLEDGEMENTS}

Thanks to the Faculty of Mechanical Engineering, Universiti Malaysia Pahang (UMP) for providing laboratory facilities and financial support under project no. RDU120103. 


\section{REFERENCES}

Buyruk, E., Johnson, M. W. and Owen, I. 1998. Numerical and experimental study of flow and heat transfer around a tube in crossflow at low Reynolds number. International Journal of Heat and Fluid Flow, 19: 223-232.

Collett, C. V. and Hope, A. D. 1983. Engineering measurements. $2^{\text {nd }}$ ed. Singapore: ELBS.

Dieck, R. H. 1997. Measurement uncertainty models. ISA Transactions, 36: 29-35.

Hausen, H. 1983. Heat transfer from tubes in counter flow, parallel flow and crossflow. USA: McGraw-Hill.

Holman, J. P. 2012. Experimental methods for engineers. $8^{\text {th }}$ ed. New York: McGrawHill.

Incropera, F. P., Dewitt, D. P., Bergman, T. L. and Lavine, A. S. 2007. Fundamentals of heat and mass transfer. $6^{\text {th }}$ ed. New York: John Wiley and Sons.

Journal of Heat Transfer Policy on Reporting Uncertainties in Experimental Measurements and Results. 1993. Editorial. Journal of Heat Transfer, 115: 5-6.

Kaptan, Y., Buyruk, E. and Ecder, A. 2008. Numerical investigation of fouling on crossflow heat exchanger tubes with conjugated heat transfer approach. International Communications in Heat and Mass Transfer, 35: 1153-1158.

Khan, M. G., Fartaj, A. and Ting, D. S.-K. 2004. An experimental characterization of crossflow cooling of air via an in-line elliptical tube array. International Journal of Heat and Fluid Flow, 25: 636-648.

Khan, W. A., Culham, J. R. and Yovanovich, M. M. 2006. Convection heat transfer from tube banks in crossflow: analytical approach. International Journal of Heat and Mass Transfer, 49: 4831-4838.

Liang, C. and Papadakis, G. 2007. Large eddy simulation of crossflow through a staggered tube bundle at subcritical Reynolds number. Journal of Fluids and Structures, 23: 1215-1230.

Mandhani, V. K., Chhabra, R. P. and Eswaran, V. 2002. Forced convection heat transfer in tube banks in crossflow. Chemical Engineering Science, 57: 379-391.

Muthucumaraswamy, R., Dhanasekar, N. and Easwara Prasad, G. 2012. Mass transfer effects on accelerated vertical plate in a rotating fluid with chemical reaction of first order. Journal of Mechanical Engineering and Sciences, 3: 346-355.

Naik, S., Probert, S. D. and Shilston, M. J. 1987. Forced-convective steady-state heat transfers from shrouded vertical fin arrays, aligned parallel to an undisturbed air-stream. Applied Energy, 26: 137-158.

Srinivasa Rao, G., Sharma, KV., Chary, S.P., Bakar, R.A., Rahman, M.M., Kadirgama, K. and Noor, M.M. 2011. Experimental study on heat transfer coefficient and friction factor of $\mathrm{Al} 2 \mathrm{O} 3$ nanofluid in a packed bed column. Journal of Mechanical Engineering and Sciences, 1: 1-15.

Suryanarayana, K.V., Srinivasa Rao, G., Reddy Prasad, D.M., Sharma, K.V. and Sarma, P.K. 2011. Experimental analysis of heat and mass transfer in a packed bed. Journal of Mechanical Engineering and Sciences, 1: 124-132.

Tahseen, A. T., Ishak, M. and Rahman, M.M. 2012a. A numerical study of forced convection heat transfer over a series of flat tubes between parallel plates. Journal of Mechanical Engineering and Sciences, 3: 271-280.

Tahseen, A.T., Ishak, M. and Rahman, M.M. 2012b. Analysis of laminar forced convection of air for crossflow over two staggered flat tubes. International Journal of Automotive and Mechanical Engineering, 6: 753-765. 
Tahseen, A. T., Ishak, M. and Rahman, M. M. 2013. A numerical study laminar forced convection of air for in-line bundle of cylinders crossflow. Asian Journal of Scientific Research, 6: 217-226.

Wang, Y. Q., Penner, L. A. and Ormiston, S. J. 2000. Analysis of laminar forced convection of air for crossflow in banks of staggered tubes. Numerical Heat Transfer Part A, 38: 319-845.

Webb, R. L. and Kim, N. H. 1994. Principl of enhanced heat transfer. $2^{\text {nd }}$ ed. New York: John Wiley and Sons.

\section{NOMENCLATURE}

\begin{tabular}{|c|c|c|c|}
\hline$A_{s}$ & tube surface area, $\mathrm{m}^{2}$ & $Q$ & heat transfer rate, $\mathrm{W}$ \\
\hline$C_{1}-C_{2}$ & $\begin{array}{l}\text { correlation/curve fit } \\
\text { coefficients }\end{array}$ & $\operatorname{Re}$ & Reynolds number \\
\hline$C_{P}$ & pressure coefficient & $T$ & temperature, ${ }^{\circ} \mathrm{C}$ \\
\hline$C_{p}$ & $\begin{array}{l}\text { specific heat capacity at } \\
\text { constant pressure, } \\
\mathrm{kJ} / \mathrm{kg}^{\circ} \mathrm{C}\end{array}$ & $U$ & velocity, $\mathrm{m} / \mathrm{s}$ \\
\hline$d$ & $\begin{array}{l}\text { small diameter of the flat tube, } \\
\mathrm{m}\end{array}$ & $V$ & voltage, $\mathrm{V}$ \\
\hline$D$ & $\begin{array}{l}\text { large diameter of the flat tube, } \\
\mathrm{m}\end{array}$ & \multicolumn{2}{|c|}{ Greek symbols } \\
\hline$D_{h}$ & $\begin{array}{l}\text { hydraulic diameter of the flat } \\
\text { tube, } m \\
\text { average heat transfer }\end{array}$ & $\Delta P$ & $\begin{array}{l}\text { pressure drop across the tube } \\
\text { array, } \mathrm{Pa}\end{array}$ \\
\hline $\bar{h}$ & $\begin{array}{l}\text { coefficient, } \\
\mathrm{W} / \mathrm{m}{ }^{\circ} \mathrm{C}\end{array}$ & $\varepsilon$ & emissivity \\
\hline$k$ & thermal conductivity, $\mathrm{W} / \mathrm{m}{ }^{\circ} \mathrm{C}$ & $\mu$ & \multirow{3}{*}{$\begin{array}{l}\text { dynamic viscosity, } \mathrm{kg} / \mathrm{m} \mathrm{s} \\
\text { Stefan-Boltzmann constant, } \\
5.670373 \times 10^{-8} \mathrm{~W} / \mathrm{m}^{2} \mathrm{~K}^{4} \\
\text { density, } \mathrm{kg} / \mathrm{m}^{3}\end{array}$} \\
\hline$I$ & current, A & $\sigma$ & \\
\hline$L$ & total length of tubes, $\mathrm{m}$ & $\rho$ & \\
\hline$n t$ & number of tubes & \multicolumn{2}{|c|}{ Subscripts } \\
\hline $\mathrm{Nu}$ & average Nusselt number & in & inlet \\
\hline$P$ & perimeter of the flat tube, $m$ & ou & outlet \\
\hline $\operatorname{Pr}$ & Prandtl number & $s$ & surface \\
\hline & & $\infty$ & free stream \\
\hline
\end{tabular}

